\title{
EGFR-TKI Sensitizing Mutation
}

National Cancer Institute

\section{Source}

National Cancer Institute. EGFR-TKI Sensitizing Mutation. NCI Thesaurus. Code 696861.

A molecular genetic abnormality indicating the presence of a sensitizing mutation in the epidermal growth factor receptor-tyrosine kinase inhibitor domain. 